\title{
Unified Control of Single-stage Z-source Grid- connected Photovoltaic System with Harmonics and Reactive Power Compensation
}

\author{
Jingwei Zhang \\ College of Energy and Electrical Engineering \\ Hohai University \\ Nanjing, China \\ Chengliang Wang \\ Jiangsu Frontier Electric Technology Co., Ltd. \\ Nanjing, China \\ Wei Han \\ College of Energy and Electrical Engineering \\ Hohai University \\ Nanjing, China
}

\begin{abstract}
Based on conventional single-stage grid-connected photovoltaic (PV) Z-source inverter, the unified control combining with harmonic and reactive power compensation is proposed. The grid harmonics and reactive current are measured while PV system outputting power. Then corresponding reactive power compensation is implemented to improve grid power factor. In this paper, the principle of boosting voltage for $\mathrm{Z}$ source network is illustrated. Harmonic measurement method based on the theory of instantaneous reactive power is applied. Then the single-neuron PID controller was designed for maximum power point tracing (MPPT) rapidly. The unified control strategy of the whole system is proposed based on S VPWM. Simulation results revealed the grid reactive power was decreased and output distorted current was improved significantly. Besides, when irradiance suddenly changed, Zsource inverter can still trace the new maximum power point, which verified proposed unified control is accurate and feasible.
\end{abstract}

Keywords-Z-source inverter; grid-connected PV system; reactive power compensation; harmonic current restrain; SVPWM; single-neuron PID

\section{INT RODUCTION}

Photovoltaic (PV) system generated power is influenced by ambient condition significantly, especially directly influenced by ambient irradiance and temperature. Two-stage gridconnected PV system has been applied. It consists Boost converter and inverter and is easy to control each part of them. However, it requires more power devices and increases energy loss of PV system[1]. Other researchers proposed single-stage inverters, which has MPPT and inverter functions synthetically. It achieves higher efficiency, but needs higher input voltage of $\mathrm{PV}$ array[1]. In recent decades, Z-source inverters were proposed and implemented in PV system[2,3]. Shoot-through

\author{
Honghua Wang* \\ College of Energy and Electrical Engineering \\ Hohai University \\ Nanjing, China \\ *Corresponding author
}

\author{
Zhebei Wang \\ College of Energy and Electrical Engineering \\ Hohai University \\ Nanjing, China
}

\section{Rong Sun}

Jiangsu Electric Power Company Research Institute Nanjing, China

duty of inverter bridge is utilized to boost output voltage of Zsource. Hence it has higher efficiency and stability.

Due to PV system develops towards larger capacity and generates power for local loads, harmonic and reactive power compensation have become another key technology for gridconnected PV system. The main circuit of three-phase inverter bridge conform the circuit of reactive power compensator. Hence it can output reactive power and reduce current distortion of grid via controlling inverter current[4].

This paper utilizes single-neuron PID (SNPID) controller to generate shoot-through duty to trace maximu moutput power of PV array. Then the shoot-through duty was combined into SVPWM to realize unified control of whole system. Simulation of proposed system was implemented for verification.

\section{CONTROL OF Z-SOURCE INVERTER AND DESIGN OF SNPID CONTROLLER}

\section{A. Control Strategy of Z-Source Inverter and Reactive Power Measurement}

Conventional Z-source network is shown in FIGURE. 1. It consists inductors and capacities which connect in X-type. The principle of boost voltage can be expressed by (1)[2, 3]:

$$
\left\{\begin{array}{l}
U_{C}=\frac{1-D_{0}}{1-2 D_{0}} U_{P V} \\
U_{Z}=\frac{1}{1-2 D_{0}} U_{P V}
\end{array}\right.
$$

where $U_{P V}$ represents output voltage of PV array, $U_{C}$ is voltage 
of capacitance in Z-source, $U_{Z}$ is $\mathrm{Z}$-source output voltage, $D_{0}$ depicts the shoot-through duty. Equation (1) indicates $U_{Z}$ can be boosted via adjusting shoot-through duty. Due to the power-voltage $(\mathrm{P}-\mathrm{V})$ characteristic of $\mathrm{PV}$ array is influenced by ambient condition significantly, PV system should both tracing MPP and boost voltage[3]. Proposed control strategy is shown in FIGURE. 1, the principle is: the outer layer voltage loop is designed for MPPT by sampling voltage and current of $\mathrm{PV}$ array. Increment conductance method is utilized to seek the voltage of maximum power point, $U_{P V}^{*}$. Then a SNPID controller is designed to obtain shoot-through duty $D_{0}$ to control PV array voltage. When $D_{0}$ is increased, $U_{Z}$, the output voltage of Z-source network, would also increase. On one hand, a PI controller is used to control $U_{Z}$ to reach its reference voltage $U_{Z}^{*}$ via adjusting current of active power $\Delta i^{*}$. On the other hand, when $U_{Z}$ is stable, due to shoot-through duty $D_{0}$ is increased, $U_{P V}$ would reduce. Finally, $U_{P V}$ can be controlled by adjusting $D_{0}$ until reaching the reference voltage $U_{P V}^{*}$.

Additionally, as FIGURE. 1 reveals, the $i p-i q$ method is used for measuring reactive power and distorted current components [4]. Firstly, a PLL is applied to achieve sinusoidal signal $\sin \omega t$ and $-\cos \omega t$, which has the same frequency and phase with A phase grid voltage $e_{a}$. Then load current is transformed under $d-q$ frame, i.e. $i_{p}$ and $i_{q}$. The matrix $C_{32}$ used in this transformation is:

$$
C_{32}=\sqrt{\frac{2}{3}}\left[\begin{array}{ccc}
1 & -\frac{1}{2} & -\frac{1}{2} \\
0 & \frac{\sqrt{3}}{2} & -\frac{\sqrt{3}}{2}
\end{array}\right]
$$

And the matrix $\mathrm{C}$ is:

$$
C=\left[\begin{array}{cc}
\sin \omega t & -\cos \omega t \\
-\cos \omega t & -\sin \omega t
\end{array}\right]
$$

Then a low pass filter is used to achieve direct component of $i_{p}$. After summing it with output signal $\Delta i_{p}{ }_{p}$, the combined current is transformed under static three-phase coordinates, $i_{a b c f}$. Hence the reference current $i_{a b c h}$, which combines active current, reactive current and distorted current components, is achieved by subtracting $i_{a b c}$ from $i_{a b c}[4]$. Reference current under $d-q$ frame $i_{d}{ }^{*}$ and $i_{q}{ }^{*}$ can be obtained via coordinate transformation.

\section{B. Design of SNPID Controller}

Due to the voltage of maximum power point is influenced directly by ambient condition, a SNPID controller is designed to trace maximu m power point faster. SNPID controller is the combination of conventional PID controller and artificial neuron network, which produces an adaptive controller. Its advantages include strong self-learning and self-organizing abilities, and is suitable for nonlinear control. The structure of SNPID controller is shown in FIGURE. 2[5].

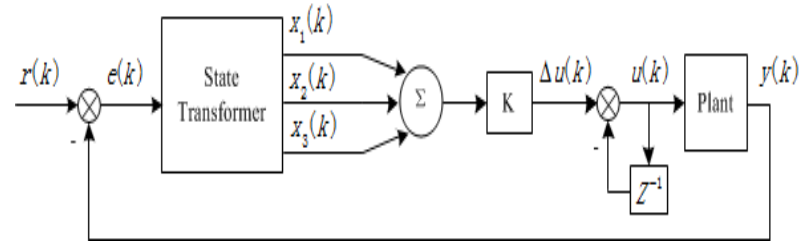

FIGURE I. ST RUCT URE OF SINGLE-NEURON PID CONT ROLLER

In FIGURE. 2, $r(k)$ and $y(k)$ are the actual and reference voltage of PV array, $e(k)$ is the error signal, $x_{1}(k), x_{2}(k), x_{3}(k)$ are inputs of controller, which is deduced via (4):

$$
\left\{\begin{array}{l}
x_{1}(k)=e(k) \\
x_{2}(k)=e(k)-e(k-1) \\
x_{3}(k)=e(k)-2 e(k-1)+e(k-2)
\end{array}\right.
$$

They represent the error signal, derivative and the second derivative of error signal, respectively. Output of controller is:

$$
u(k)=u(k-1)+K \sum_{i=1}^{3} \frac{W_{i}(k)}{\sum_{i=1}^{3}\left|W_{i}(k)\right|} x_{i}(k)
$$

$K$ is the gain coefficient, which directly influences system stability and response speed. $w_{i}(k)$ is adjustable weight. In this paper, the supervisory Hebbian rule is utilized for training weights, which is expressed as follows [5]:

$$
\left\{\begin{array}{l}
W_{1}(k)=W_{1}(k-1)+\eta_{P} e(k) u(k)(e(k)-\Delta e(k)) \\
W_{2}(k)=W_{2}(k-1)+\eta_{I} e(k) u(k)(e(k)-\Delta e(k)) \\
W_{3}(k)=W_{3}(k-1)+\eta_{D} e(k) u(k)(e(k)-\Delta e(k))
\end{array}\right.
$$

where $\eta_{P}, \eta_{I}, \eta_{D}$ are learning rates for proportion, integration and derivate process. They are chosen as different constants to adjust each weight. Due to parameters are self-adaptable, $D_{0}$ can be adjusted rapidly to control the voltage of PV array.

\section{UNIFIED CONTROL BASED ON SVPWM}

\section{A. SVPWM Control of Z-Source Inverter}

Space vector pulse width modulation (SVPWM) has advantages of low harmonic components and high utilization of DC voltage. In this paper, SVPWM is applied in Z-source inverter. However, the shoot-through duty should be inserted into modulation to boost voltage of Z-source. Based on the conventional SVPWM, a common method is insert shootthrough time, $T_{S T}$, into transition of two adjacent vectors [6,7]. In order to reduce switching loss of power devices, the symmetric 5 non-shoot-through vectors are combined with shoot-through vector. For instance, in sector I, the conducting sequences of 6 power devices in FIGURE. $1, S_{1}$ to $S_{6}$, are shown in FIGURE. 3. The shaded areas represent shootthrough time $T_{S T}$, and it is divided into 4 parts in one switching period. 


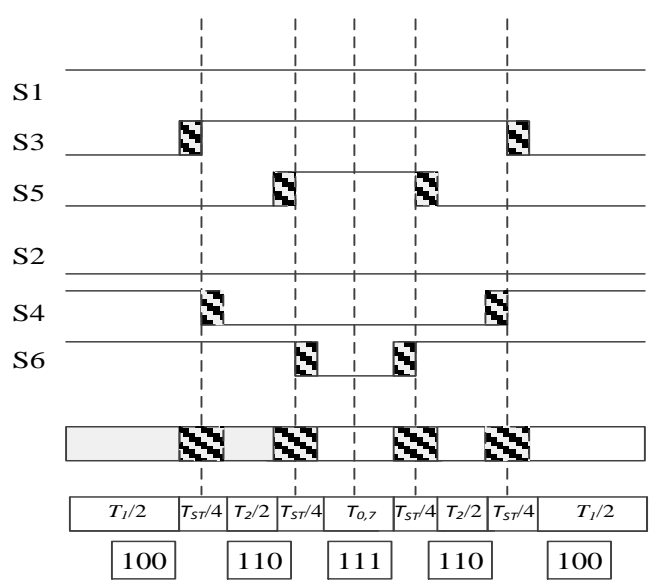

FIGURE II. SVPWM SWITCHING SIGNALS IN SECTOR I

Hence, the switch period Ts can be expressed as follows:

$$
T_{S}=T_{1}+T_{2}+T_{0,7}+T_{S T}
$$

$T_{1}, T_{2}, T_{0,7}$ are operating time of traditional space vector $\mathrm{V}_{1}$, $\mathrm{V}_{2}$ and $\mathrm{V}_{0}$ or $\mathrm{V}_{7}$ of sector $\mathrm{I}$. The conducting sequences in other 5 sectors are also omitted due to the similarity.

\section{B. Control of Inverter Current}

Based on modified SVPWM mentioned above, the inverter current loop is controlled by grid voltage orientation decouple method[6], as shown in FIGURE. 1. The mathe matical model of main inverter circuit can be described as follows:

$$
\left\{\begin{array}{l}
e_{d}=L_{F} \frac{d i_{d}}{d t}-\omega L_{F} i_{q}+u_{d} \\
e_{q}=L_{F} \frac{d i_{q}}{d t}+\omega L_{F} i_{d}+u_{q}
\end{array}\right.
$$

Under $d-q$ frame, $e_{d}$ and $e_{q}$ are components of grid voltage, $u_{d}$ and $u_{q}$ are the components of voltage on the grid side, $i_{d}$ and $i_{q}$ are components of inverter current, respectively. $L_{F}$ is reactor inductance in FIGURE. 1. So a decoupled PI controller is applied to control grid voltage:

$$
\left\{\begin{array}{l}
u_{d}=-\left(K_{p}+\frac{K_{i}}{S}\right)\left(i_{d}^{*}-i_{d}\right)+\omega L_{F} i_{q}+e_{d} \\
u_{q}=-\left(K_{p}+\frac{K_{i}}{S}\right)\left(i_{q}^{*}-i_{q}\right)-\omega L_{F} i_{d}+e_{q}
\end{array}\right.
$$

$K_{p}$ and $K_{i}$ are the gain and integral coefficients of PI controller, respectively. This decoupling approach realize inverter current $i_{d}$ and $i_{q}$ can be controlled independently to trace the reference current signal $i_{d}{ }^{*}$ and $i_{q}{ }^{*}$, as FIGURE. 1 shows.

\section{SIMULATION AND ANALYSIS}

In order to verify the accuracy and feasibility of proposed unified control of Z-source grid-connected PV system with harmonic and reactive power compensation, the simulation model of a $3 \mathrm{~kW}$ PV system is designed in MATLAB/Simu link. Considering the voltage and current ripple of capacitors and inductors of Z-source, parameters are designed as: $L_{1}=L_{2}=500 \mu \mathrm{H}, C_{1}=C_{2}=470 \mu \mathrm{F}$. Besides, $13 \mathrm{PV}$ modules, TSM240W, which are produced by Trina Solar Ltd., are connected in series to form the PV array. It is modeled by model of Luft et al.[8]. Grid phase to phase voltage is $380 \mathrm{~V}$ and the frequency is $50 \mathrm{~Hz}$. Nonlinear load is formed by three-phase diodes rectifier with resistors and inductors, which costs active power $7.5 \mathrm{~kW}$ and reactive power $0.558 \mathrm{kVar}$.

Firstly, ambient condition of simulation is set as standard test condition (STC). FIGURE. 4 reveals A phase inverter current $I_{a_{-} P V}$, nonlinear load current $I_{a_{-} \text {load }}$ and grid current $I_{a_{-} \text {grid }}$, when system operates under stable state. Before Zsource inverter connect to the grid, grid current curve is $I_{a_{-} \text {load }}$ in FIGURE. 4, THD is $7.9 \%$, as FIGURE. 5(a) shows. After inverter connects to the grid, grid current $I_{a_{\text {grid }}}$ is shown in FIGURE. 4, its THD decreases to $4.11 \%$, as shown in FIGURE. 5(b). Besides, PV system compensates reactive power, as FIGURE. 6 shows, inverter generates active power $1 \mathrm{~kW}$ and reactive power $0.215 \mathrm{kVar}$ in A phase. Grid outputs active power $1.5 \mathrm{~kW}$ in A phase, which verifies the accuracy of unified control with harmonic and reactive power compensation. FIGURE. 7 shows the output voltage of $\mathrm{Z}$ source $U_{Z}$ and voltage of $\mathrm{PV}$ array $U_{P V}$ in stable state. $U_{Z}$ fluctuates slightly, $U_{P V}$ is agree with reference voltage, $395 \mathrm{~V}$.

Additionally, in order to verify the feasibility of proposed SNPID controller, the irradiance of PV array changes from $800 \mathrm{~W} / \mathrm{m}^{2}$ to $1200 \mathrm{~W} / \mathrm{m}^{2}$ at $1 \mathrm{~s}$. Corresponding output power of $\mathrm{PV}$ array changes from $2.463 \mathrm{~kW}$ to $3.819 \mathrm{~kW}$, as shown in Fig 8(a). FIGURE. 8(b) shows the response curves of PV array power which are controlled by conventional PID and SNPID controller, respectively. When system starts and irradiance step changes, the SNPID controller can trace the maximum power point faster than PID controller, which reveals it is much suitable for conditions that irradiance sudden changes.

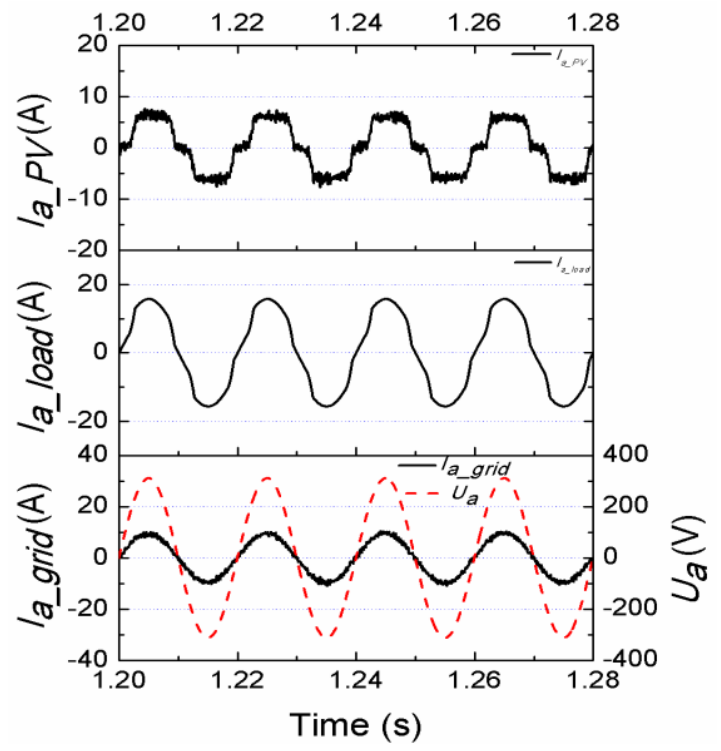

FIGURE III. CURRENT CURVES OF PROPOSED SYSTEM IN STEADY ST ATE 


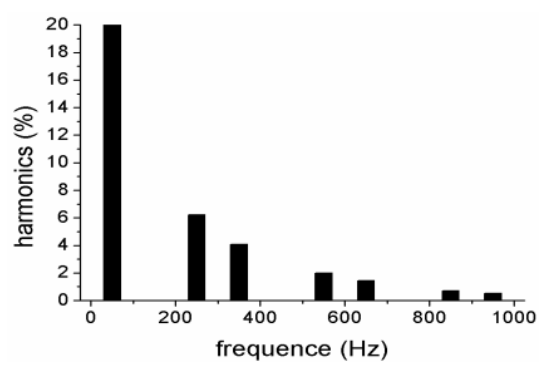

(A)

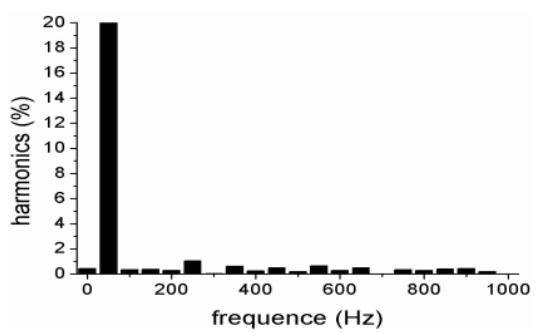

(B)

FIGURE IV. HARMONIC OF GRID CURRENT: (A) THD BEFORE COMPENSATION, (B) THD AFTER COMPENSATION

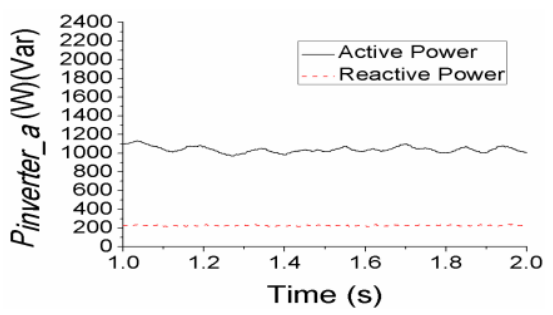

(A)

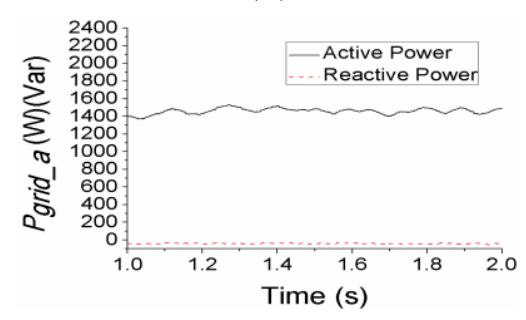

(B)

FIGURE V. ACTIVE AND REACTIVE POWER CURVES AFTER SY STEM ST ART S: (A) GENERATEDPOWER OF INVERTER IN A PHASE, (B) GRID POWER IN A PHASE

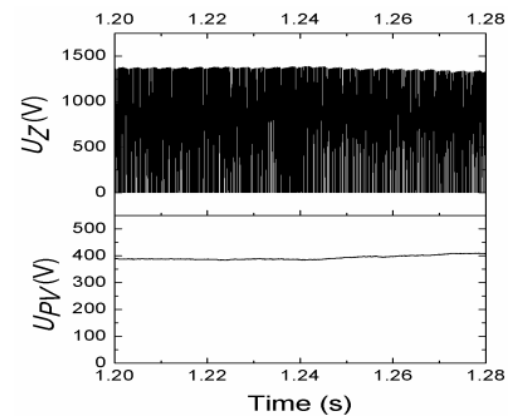

FIGURE VI. OUTPUT VOLTAGE CURVES OF Z-SOURCE AND PV ARRAY IN STEADY ST ATE

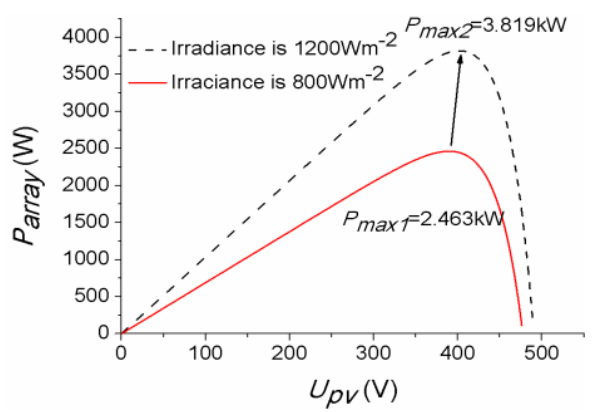

(A)

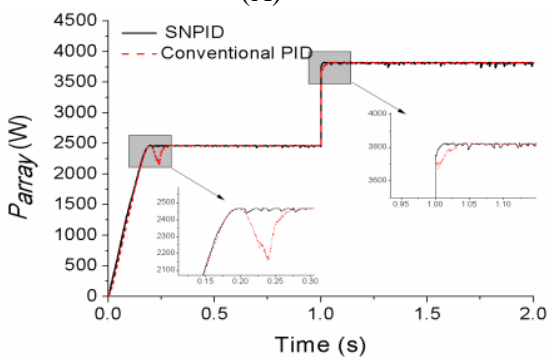

(B)

FIGURE VII. SIMULATION RESULTS WHEN IRRADIANCE CHANGES (A) VARIATION OF PV ARRAY OUTPUT POWER, (B) PERFORMANCE OF SNPID AND PID CONT ROLLER

\section{CONCLUSIONS}

It is feasible to combine conventional Z-source gridconnected PV system with harmonic and reactive power compensation. In this paper, the unified control strategy of Zsource inverter, harmonic and reactive power compensation is proposed. Simulation result shows the PV system restrains grid harmonic current and compensate reactive power. Besides, the SNPID controller has superior dynamic performance and enhances speed of MPPT. The proposed unified controlled system has compact structure and is equipped with high efficiency Z-source inverter. It can also improve power quality of grid significantly.

\section{ACKNOWLEDGMENT}

This research was supported by a grant from the State Grid electric power company project of China (No.J2014028).

\section{REFERENCES}

[1] S. B. Kjaer, J. K. Pederson, F. Blaabjerg, "A review of single-phase grid-connected inverters for photovoltaic modules," IEEE Trans. Industry Applications, vol. 41, no. 5, pp. 1292-1306, Sept. 2005.

[2] F. Z. Peng, A. Joseph, J. Wang, et al., "Z-source inverter for motor drives," IEEE Trans. Power Electronics, vol. 20, no. 4, pp. 857-863, Jul. 2005.

[3] S. Yang, X. Ding, F. Zhang, et al, "Unified control technique for Zsource inverter," presented at the IEEE Power Electronics Specialists Conf. (PESC) 2008, Rhodes, Greece, Jun. 15-19, 2008.

[4] L. Wu, Z. Zhao, J. Liu, "A single-stage three-phase grid-connected photovoltaic system with modified MPPT method and reactive power compensation,” IEEE Trans. Energy Conversion, vol. 22, no.4, pp. 881886, Dec. 2007.

[5] D. Sun, J. Meng, "A single neuron PID controller based PMSM DTC drive system fed by fault tolerant 4-switch 3-phase inverter," presented at the 1st IEEE Conf. on Industrial Electronics and Application, Singapore, Singapore, May. 24-26, 2006.

[6] K. Q. Qu, Q. Q. Niu, C. Yang, J. B. Zhao, "Battery Charge-Discharge Control Strategy Based on the Single Z-Source Three-Level SVPWM 
Inverter," presented at the 2013 IEEE Int. Conf. on Applied Superconductivity and Electromagnetic Devices (ASEMD), Beijing, China, Oct. 25-27, 2013.

[7] J. Ding, S. Xie, Y. Tang, et al. "Optimal design of the inductor in Zsource inverter with single phase shoot-through SVPWM strategy". presented at the 2010 IEEE Energy Conversion Congress and Exposition (ECCE),. Atlanta, GA, Sept. 12-16, 2010.

[8] W. De Soto, "Improvement and validation of a model for photovoltaic array performance", M.S. thesis, Solar Energy Laboratory, Univ. of Wisconsin-Madison, Madison, WI, 2004.

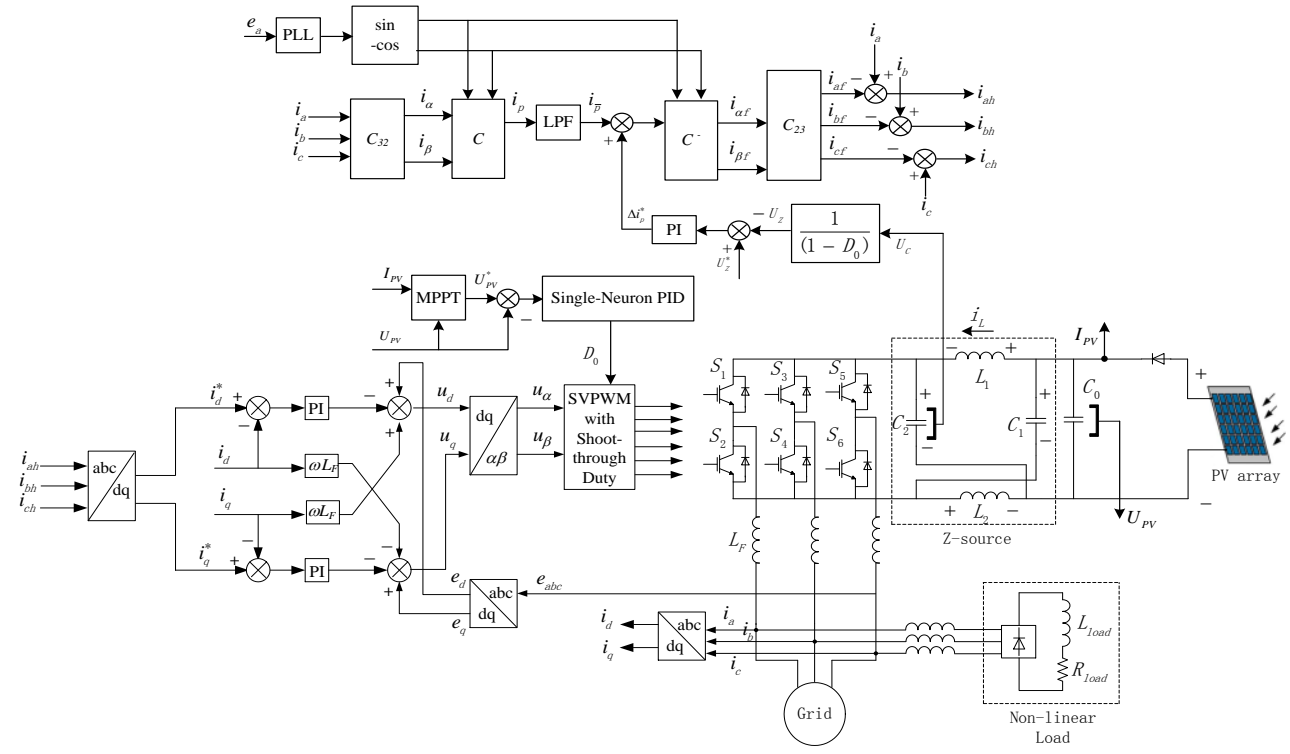

FIGURE VIII. DIAGRAM OF UNIFIED CONTROL OF SINGLE STAGE Z-SOURCE GRID-CONNECTED PV INVERTER AND REACTIVE POWER COMPENSATION. 